\title{
Use of secondary prophylaxis against myocardial infarction in the north of England
}

\author{
Martin Eccles, Colin Bradshaw
}

\begin{abstract}
Objective-To record the use of secondary prophylactic drugs in patients discharged from hospital having had a myocardial infarction.

Design-Prospective postal questionnaire survey of a random one in two sample of general practitioners in the region.

Setting-The nine family practitioner committee areas within the Northern Regional Health Authority.

Patients-Patients who had had a myocardial infarction and were discharged to their general practitioner.
\end{abstract}

Main outcome measure-Whether $\beta$ blockers or aspirin, or both, were given on discharge.

Results-Of 267 patients, $158(59 \%)$ were treated suboptimally in that they did not receive a secondary prophylactic drug to which they had no contraindication. For most patients this entailed underuse of one drug, but $17(6 \%)$ of patients received no treatment. $\beta$ Blockers were 2.5 times less likely to be used than aspirin. Treatment was not associated with the age or sex of the patient, risk of further infarction, or hospital of discharge.

Conclusions-Secondary prophylaxis after myocardial infarction is practised haphazardly. It should be offered to all patients who can tolerate it, after a trial period to assess any side effects of the drugs if necessary.

Research, University of

Newcastle upon Tyne,

Newcastle upon Tyne NE2

4AA

Martin Eccles, MD, clinical

research associate

Marsden Road Health Centre, South Shields, Tyne and Wear NE34 6RE. Colin Bradshaw, MRCP, general practitioner

Correspondence to: $\mathrm{Dr}$ Martin Eccles, Prospect House Medical Group, Newcastle upon Tyne NE4 6QD.

BMF 1991;302:91-2

\section{Introduction}

After a period of equivocation about the role and effectiveness of prophylactic drugs after myocardial infarction ${ }^{2}$ the advice given on the use of such drugs has become much clearer. $\beta$ Blockers reduce early and late mortality after infarction and should be prescribed to all patients who can tolerate them for at least a year and possibly up to six years. ${ }^{34}$ The benefit of aspirin has also been proved, ${ }^{5}$ though the advice on duration of treatment is less precise. ${ }^{367}$ Given that the two drugs work in different ways, it is logical to use both wherever possible. ${ }^{3+6}$ Treatment is best started as soon as possible, ${ }^{+5}$ so patients should be discharged receiving treatment that should then be continued within primary care.

Number (percentage) of patients who had had myocardial infarction discharged from hospital receiving $\beta$ blockers or aspirin, or both, according to whether they had contraindications to either drug

\begin{tabular}{lllccc}
\hline & \multicolumn{4}{c}{ Aspirin } \\
\cline { 3 - 6 }$\beta$ & $\begin{array}{l}\text { No treatment, no } \\
\text { contraindications }\end{array}$ & $\begin{array}{c}\text { Treatment, no } \\
\text { contraindications }\end{array}$ & $\begin{array}{c}\text { No treatment, } \\
\text { contraindications }\end{array}$ & $\begin{array}{c}\text { Treatment, } \\
\text { contraindications }\end{array}$ \\
\hline \multirow{3}{*}{ Blockers } & $\begin{array}{l}\text { No treatment, } \\
\text { no contraindications }\end{array}$ & $17(6 \cdot 4)$ & $91(34 \cdot 1)$ & $7(2 \cdot 6)$ & $4(1 \cdot 5)$ \\
$\begin{array}{l}\text { Treatment, } \\
\text { no contraindications }\end{array}$ & $14(5 \cdot 2)$ & $59(22 \cdot 1)$ & $2(0 \cdot 7)$ & $1(0 \cdot 4)$ \\
$\begin{array}{l}\text { No treatment, } \\
\text { contraindications } \\
\text { Treatment, } \\
\text { contraindications }\end{array}$ & $18(6 \cdot 7)$ & $42(15 \cdot 7)$ & $6(2 \cdot 2)$ & $1(0 \cdot 4)$ \\
\hline
\end{tabular}

A study that we conducted locally in Tyneside in June 1989 suggested that secondary prophylactic drugs were not being widely used (unpublished data). To determine whether this was a local or more general phenomenon we conducted a postal questionnaire survey of general practitioners, collecting data on patients discharged from hospitals across the Northern Regional Health Authority after having had a myocardial infarction.

\section{Methods}

The survey sample was a one in two random sample of the general practitioners in the Northern Regional Health Authority, stratified by family practitioner committee.

The general practitioners were sent a questionnaire on a single sheet of A4 paper. One side comprised a covering letter, which introduced and explained the study and asked for details from the hospital discharge letter and general practice notes of the next patient discharged to the practitioner after having had a myocardial infarction. The other side was to be completed with the patient's details and asked for the patient's age, sex, and the hospital he or she was discharged from; whether the patient had a high risk of further infarction or sudden death; whether he or she was taking $\beta$ blockers or aspirin, or both, on admission to or discharge from hospital; and whether the patien had contraindications to either of these drugs. The general practitioners were asked to return a blank form if they had not had an eligible patient during the study; they were also given the option of declining to participate in the study.

We required the name of the hospital from which patients were discharged because 13 of the hospitals in the region were participating in the Third International Study of Infarct Survival (ISIS-3), which required patients to be discharged taking aspirin, and we needed to be able to identify such patients.

We defined the patient as being at a high risk of further infarction or sudden death if he or she had any of the following: a previous infarct to the one for which he or she had been admitted; extensive infarction (mentioned in the letter); arrhythmias; or left ventricular failure.

Contraindications to $\beta$ blockers were defined as diabetes mellitus ${ }^{89}$ peripheral vascular disease, and asthma or bronchitis or wheezing, ${ }^{10}$ and space was available for respondents to enter any other reason they thought was a contraindication. Contraindications to aspirin were defined as sensitivity to aspirin, an active duodenal ulcer, or taking anticoagulants. ${ }^{10}$ Space was again available for other specified reasons.

Questionnaires were posted with a reply envelope with the postage paid at the start of the study and at intervals of two weeks thereafter for six weeks. Respondents were removed from the list for subsequent 
postings. The final letter was marked with highlighted stickers, and general practitioners who had not had an eligible patient were asked to return the form uncompleted.

Statistical analysis of the results was performed by the $\chi^{2}$ test with the Statistical Package for the Social Sciences.

The study was approved by all the ethical committees in the Northern region and was funded by the Scientific Foundation Board of the Royal College of General Practitioners

\section{Results}

Out of 837 questionnaires posted we received 498 replies $(59 \cdot 5 \%)$, of which 267 were notifications of patients who had had a myocardial infarction and 231 were from general practitioners who had not had an eligible patient.

There were replies for 191 men and 76 women, a ratio of $2 \cdot 5: 1 \cdot 0$. The results were analysed to look at the differences between patients at high risk of further myocardial infarction or sudden death and those at low risk, those in hospitals participating in the Third International Study of Infarct Survival and those in hospitals not participating in the study, and both of these comparisons with respect to patients' sex. In each case there was no significant difference between the groups.

The table shows the use of prophylactic drugs on discharge and the prevalences of contraindications to treatment. In all, 195 of the 267 patients were eligible to receive $\beta$ blockers, of whom only 76 did, and 244 were eligible to receive aspirin, of whom 195 did. A total of 181 patients were eligible to receive both drugs, and only 59 did.

The patients were divided into the two groups: those receiving optimum treatment - those patients treated with both drugs and those not treated because of contraindications (the centre four cells of the table) and those receiving suboptimum treatment (any patients not in the first group). There was no significant difference between these two groups in terms of age or sex, high or low risk of further infarction or sudden death, or whether they were discharged from a hospital participating in the Third International Study of Infarct Survival or a hospital not participating in the study.

\section{Discussion}

This study shows that in the Northern region many patients $(158 / 267 ; 59 \%)$ who had survived a myocardial infarction were discharged from hospital receiving suboptimum treatment, and this was 2.5 times more likely to be due to underuse of $\beta$ blockers rather than underuse of aspirin. For most of these patients suboptimum treatment meant being appropriately treated with one drug but not getting the other, to which they had no contraindications. For $17(6 \%)$ of the total number of patients suboptimum treatment mean receiving no treatment at all. Patients at high risk of a further myocardial infarction or sudden death were as likely to be treated suboptimally as any others.

We have no reason to think that our sample is not representative. Given an average list size of $2193,{ }^{11}$ an incidence of acute myocardial infarction of $0.0019 \%,{ }^{11}$ and an $80 \%$ survival, ${ }^{12}$ we would have expected to have received details of 320 patients. The 267 replies gave us data on $83 \%$, a high response for a postal questionnaire. The age and sex distribution of the patients was very similar to that previously reported..$^{112}$

The use of secondary prophylaxis has not been previously recorded, though unpublished data from the Second International Study of Infarct Survival ${ }^{13}$ also found an underuse of $\beta$ blockers on discharge from hospital, which was not subsequently compensated for by treatment initiated by general practitioners. ${ }^{4}$ Despite the current Third International Study of Infarct Survival, $18 \%$ of the patients were not given aspirin but had no contraindications to treatment. Such patients were as likely to be discharged from hospitals participating in the Third International Study of Infarct Survival as those not participating. It seems that the use of secondary prophylactic drugs is haphazard, particularly in the case of $\beta$ blockers, for which of the 195 patients with no contraindications to treatment, only 76 received the drugs. Although our data can offer no insight, there is a worry that treatment not initiated in hospital will never be given.

The logic for giving two prophylactic drugs is strong. $\beta$ Blockers lower the heart rate, decrease the force of contraction, and lower blood pressure, ${ }^{4}$ while aspirin has an antithrombotic action. ${ }^{6}$ Their protective effects should be at least additive, and both drugs can be used after thrombolytic treatment. Though no trial has looked specifically at a combination of a $\beta$ blocker and aspirin, a trial comparing aspirin, dipyridamole, and placebo found among patients receiving active treatment a greater reduction in mortality and incidence of further infarction in those patients also taking $\beta$ blockers. ${ }^{14}$

From our data we have no clear idea of the reasons why treatment was not given, but one potential problem was that of contraindications to the drugs. In the section for other contraindications several reasons for avoiding treatment were given that could be understood only by individual case analysis (for example, response to previous treatment). The decision whether or not to treat has to rest with the clinician responsible for the patient's care, and pharmacological reasons for not giving treatment may form only part of the picture. Equal consideration may have to be given to the need to avoid polypharmacy in an elderly patient. If there is any doubt about the veracity of a patient's intolerance of a drug, however, they should be given a therapeutic trial and then reviewed. In the absence of contraindications treatment not initiated in hospital should be started by the general practitioner.

We are left reflecting on the opinion of Julian et al that "doctors have a poor record of translating the findings of clinical trials into practice," the apparently unheeded advice that $\beta$ blockers and aspirin should be given after myocardial infarction to all patients who can tolerate them.

1 Hampton JR, Breckenridge A, Rose G. Should every survivor of a heart attack be given a beta blocker? $B M 7$ 1982;285:33-40.

2 Anonymous. Aspirin after myocardial infarction [Editorial]. Lancet 1980;i: $1172-3$

3 Bloomficld P. After the infarct. BMF 1987;295:1431-2.

4 Beta blockade after acute myocardial infarction. Drug Ther Bull 1990;28:47-8.

5 Second International Study of Infarct Survival (ISIS-2) Collaborative Group. Randomised trial of intravenous streptokinase, oral aspirin, both, or neither among 17187 cases of suspected acute myocardial infarction: ISIS-2. Lancet 1988;ii:349-60.

6 Aspirin and myocardial infarction. Drug Ther Bull 1987;25:17-9.

7 Orme M. Aspirin all round? BMJ 1988;296:307-8.

8 Hansteen V, Moinichen E, Lorentsen E, et al. One year's treatment with propranolol after myocardial infarction: preliminary report of Norwegian multicentre trial. BMF 1982;284:155-60.

9 Kaplan NM, Rosenstock J, Ruskin P. A differeing view of treatment of hypertension in patients with diabetes mellitus. Arch Intern Med 1987;147: $1160-2$

10 Joint Formulary Committee. British national formulary. London: BMA, 1990.

11 Royal College of General Practitioners, Office of Population Censuses and Surveys, Department of Health and Social Security. Morbidity statistics from general practice. Third national study, 1981-2. London: HMSO, 1986.

12 Fry J. Common diseases, their nature, incidence and care. London: Hastings Hilton, 1979.

13 Second International Study of Infarct Survival (ISIS-2) Collaborative Group. Lancet 1988;ii:349-60.

14 Persantin-Aspirin Reinfarction Study Research Group. Part 2. Secondary coronary prevention with persantin and aspirin. I Am Coll Cardiol 1986;7:251-69

15 Julian DG, Pentecost BL, Chamberlain DA. A milestone for myocardial infarction. BMF 1988;297:497-8.

(Accepted 17 October 1990 ) 